\title{
Estimation of New Tetraploid Apple Forms as Donors of Diploid Gametes for Selection on a Polyploidy Level
}

\author{
G. A. Sedysheva*, N. G. Gorbacheva \\ SSI All Russian Research Institute of Fruit Crop Breeding, Orel, Russia \\ *Corresponding Author: nauka@vniispk.ru
}

Copyright (C) 2013 Horizon Research Publishing All rights reserved.

\begin{abstract}
The comparative analysis of meiosis in a process of microsporogenesis in a number of new tetraploid apple forms is given. The suitability of these apple forms for the application in breeding on a polyploidy level as donors of diploid gametes have been determined. Forms 25-37-47 (SR0523, 2x X Antonovka ploskaya, 4x) and 30-47-88 (Liberty, 2x X 13-6-106, 4x) are especially valuable as initial forms for breeding, since they give a sufficient amount of the fertile pollen and carry genes of immunity to scab: Form 25-37-47 carries gene $V_{m}$ and Form 30-47-88 carries gene $V_{f}$ that is very important for the development of new adaptive and high-qualitative triploid apple cultivars.
\end{abstract}

Keywords Apple, Tetraploids, Triploids, Cultivar, Meiosis, Microsporogenesis, Microspores, Gametes, Donor

\section{Introduction}

The tendency of the environmental deterioration through numerous stresses of the biological and technogenic character leads to the lowing of apple adaptativity and quality of apple production. So, breeders constantly have to improve the fruit assortment, replenish it with new cultivars with high resistance and adaptivity. Using polyploidy in apple breeding is one of the methods favoring the fulfilling of this goal. Generally, from crossings of different-chromosomal apple forms (diploid $\mathrm{x}$ tetraploid; tetraploid $\mathrm{x}$ diploid) the triploid progeny is formed. A high value of triploid apple cultivars was often confirmed (Tuz, Lozitsky, 1970 [1]; Bacharach ,1982 [2]; Singh, Wafai, 1984 [3]; Barletta, 1988 [4], etc.). It was noted that triploid cultivars not infrequently have higher economically valuable traits than diploid ones. In this connection, the mass obtaining of triploid hybrids will give a chance to select promising cultivars meeting the requirements of the intensive adaptive horticulture. A scanty set of initial tetraploid forms-donors of diploid gametes is one of the limited factors for a successful fulfillment of this goal.

At the All Russian Research Institute of Fruit Crop Breeding the apple breeding on a polyploidy level has been carried out since 1970 . For this period a number of triploid cultivars have been developed from different-chromosomal crossings. Part of them has been regionalized another part is on the state trials. Besides, a number of tetraploid forms have been obtained, which are of interest for use in further breeding. In breeding respect these forms are of equal value. In the hybrid progeny obtained from crossings of diploid cultivars with tetraploid forms when a tetraploid form is a pollinator, different pollinators provide different output of polyploid plants in a hybrid progeny, i.e. a quality of male gametes in different forms is different. A percent of triploid seedlings in different combinations of crossings varies from 0 to $100 \%$. In connection with such differences the data on a meiosis process in the microsporogenesis can become a key for understanding such differences and will give a chance to estimate these forms from the point of their suitability for crossings with the purpose of mass obtaining of triploids and the following selection of new cultivars.

Both in foreign and Russian literature the questions of microsporogenesis and formation of male gametophyte in diploid and triploid apple cultivars have been elucidated fully enough (Schoemaker, 1926 [7]; Rybin, 1927 [8]; Heilborn, 1928 [9]; Darlington, Moffett, 1930 [10]; Ivanovskaya, 1962 [11]; Konstantinov, 1971 [12]; Radionenko, 1972 [13]; Krylova, 1981 [14]; Singh, Wafai, Koul, 1985 [15]; Singh, Wafai, 1984 [3]; etc.). As regards the similar information in tetraploid apple cultivars, such reports are met very seldom. Nebel, 1929 [16] only gave the description of individual stages of meiosis in two tetraploid apple species: Malus coronaria Mill. and Malus glaucescens Rehd. The author had a goal only studying a number of chromosomes but not the systematic investigation of meiosis. The meiosis process in tetraploid cv. Hibernal was described most fully in the report of Vaarama, 1948 [17]. Probably, weak interest for studying the generative sphere in tetraploid forms is explained by their low economic value. The situation is being changed in connection with the development of apple breeding with the use of tetraploid forms as initial forms for hybridization. Knowledge of the features of the formation of generative structures of initial forms will allow determining the value of each concrete form as a donor of diploid gametes, which has a decisive factor in 
the selection of initial pairs for hybridization for the purpose of mass obtaining of tripolids.

At the All Russian Research Institute of Fruit Crop Breeding (VNIISPK, Orel, Russia) the section of apple breeding on a polyploidy level has been included in the program of investigations. The systematic study of generative structures in tetraploid forms used for hybridization is carried out (Sedysheva, 1985 [18]; 1998 [19]; Sedysheva, Knyazeva, 2000 [20]; 2007 [21]; etc.).

\section{Methodology}

Homozygous tetraploids obtained at the All Russian Research Institute of Fruit Crop Breeding in a process of the realization of the breeding program on a polyploidy level in crossings $4 \mathrm{x} \times \mathrm{x}$, 4x $\mathrm{x} 2 \mathrm{x}, 2 \mathrm{x} \mathrm{x}$ 4x: Form 25-35-121 (Wealthy, 4x x Papirovka, 4x), 20-9-27 (Wealthy, 4x x
Antonovka obyknovennaya, 2x), 25-37-47 (SR0523, 2x x Antonovka ploskaya, 4x) and Form 30-47-88 (Liberty, 2x x 13-6-106, 4x) served as objects for study of male gametophyte formation.

Meiosis in a process of microsporogenesis was studied on temporary pressed preparations prepared by aceto-hematoxylin method (Topilskaya, Luchnikova, Chuvashina, 1975 [5]). The mixture of alcohol and ice-cold acetic acid was used for the purpose of fixation (3 parts of absolute alcohol and 1 part of ice-cold acetic acid). The fixation was begun at the phase of appearance of a green cone in a flower bud and it was made daily till the moment of florescence. The preparations were looked over with microscope Nikon 50i with camera DS-Fi 1.

200-400 microsporocytes were looked over on each stage of meiosis.

Table 1. Number of disorders in the process of microsporogenesis in new tetraploid apple forms (percent)

\begin{tabular}{|c|c|c|c|c|}
\hline \multirow{2}{*}{$\begin{array}{l}\text { Ferm } \\
\text { Meiosis } \\
\text { stage }\end{array}$} & \multicolumn{4}{|c|}{ Disorders, $\%$} \\
\cline { 2 - 5 } & $25-37-47$ & $20-9-27$ & $25-35-121$ & $30-47-88$ \\
\hline Metaphase-I & 17,5 & 22,0 & 20,5 & 38,7 \\
\hline Anaphase-I & 34,1 & 36,1 & 15,4 & 44,1 \\
\hline Telophase-I & 9,1 & 8,0 & 6,8 & 19,9 \\
\hline Metaphase-II & 22,5 & 33,1 & 13,2 & 51,3 \\
\hline Anaphase-II & 22,5 & 28,8 & 17,2 & 32,5 \\
\hline Telophase-II & 8,7 & 7,7 & 12,0 & 27,2 \\
\hline Tetrads & 10,9 & 7,2 & 42,2 & 46,4 \\
\hline
\end{tabular}

Variations were observed only in a number of disorders and diversity of their typed (Table 2).

Table 2. The diversity of disorder types in the process of microsporogenesis in tetraploid apple forms

\begin{tabular}{|c|c|c|c|c|}
\hline Form & $25-37-47$ & $20-9-27$ & $25-35-121$ & $30-47-88$ \\
\hline $\begin{array}{c}\text { Meiosis } \\
\text { stage }\end{array}$ & 1,2 & $1,2,24$ & $1,2,11$ & $1,2,3,4,8,24$ \\
\hline Metaphase-I & 7,9 & $2,7,8,9$ & $1,2,7,9$ & $2,7,8,9,24$ \\
\hline Anaphase-I & $7,12,15$ & 12,15 & $7,12,15,26$ & 12 \\
\hline Telophase-I & $1,2,8$ & $1,2,8,24$ & $1,2,15$ & $1,2,3,6,8,11,24,25$ \\
\hline Metaphase-II & $8,9,24$ & $2,7,8,9,24$ & $2,7,8,9$ & $2,7,8,9,24,25$ \\
\hline Anaphase-II & 7,12 & $7,8,12,15$ & 15 & $12,15,24,26$ \\
\hline Telophase-II & 16,17 & $16,17,18$ & $12,16,21,22$ & $16,17,18$ \\
\hline Tetrads & & & \\
\hline
\end{tabular}

Notes: 1 - getting ahead of separate chromosomes to the poles of division spindle; 2 - throwing of one or several chromosomes outside of achromatinic spindle; 3 - diffuse distribution of chromosomes along the whole spindle; 4 - micro spindle; 5 - three-stripe spindle; 6 - microsporocyte without chromatin; 7 - bridge; 8 combination of two disorder types; 9 - belated division of a part of bivalents or chromosomes in the center of spindle of division (backwardness); 10 - spindle splitting; 11 - unequal groups of chromosomes; 12 - micronuclei (1-4); 13 - nuclei of irregular form; 14 - unequal nuclei; 15 - over-numerous nuclei of different size; 16 - pentads; 17 - hexads; 18 - heptads; 19 - octads; 20 - nonads; 21 - monads; 22 - diads; 23 - triads; 24 - over-numerous spindles; 25 - asynchronous division; 26 - degeneration of chromatin. 


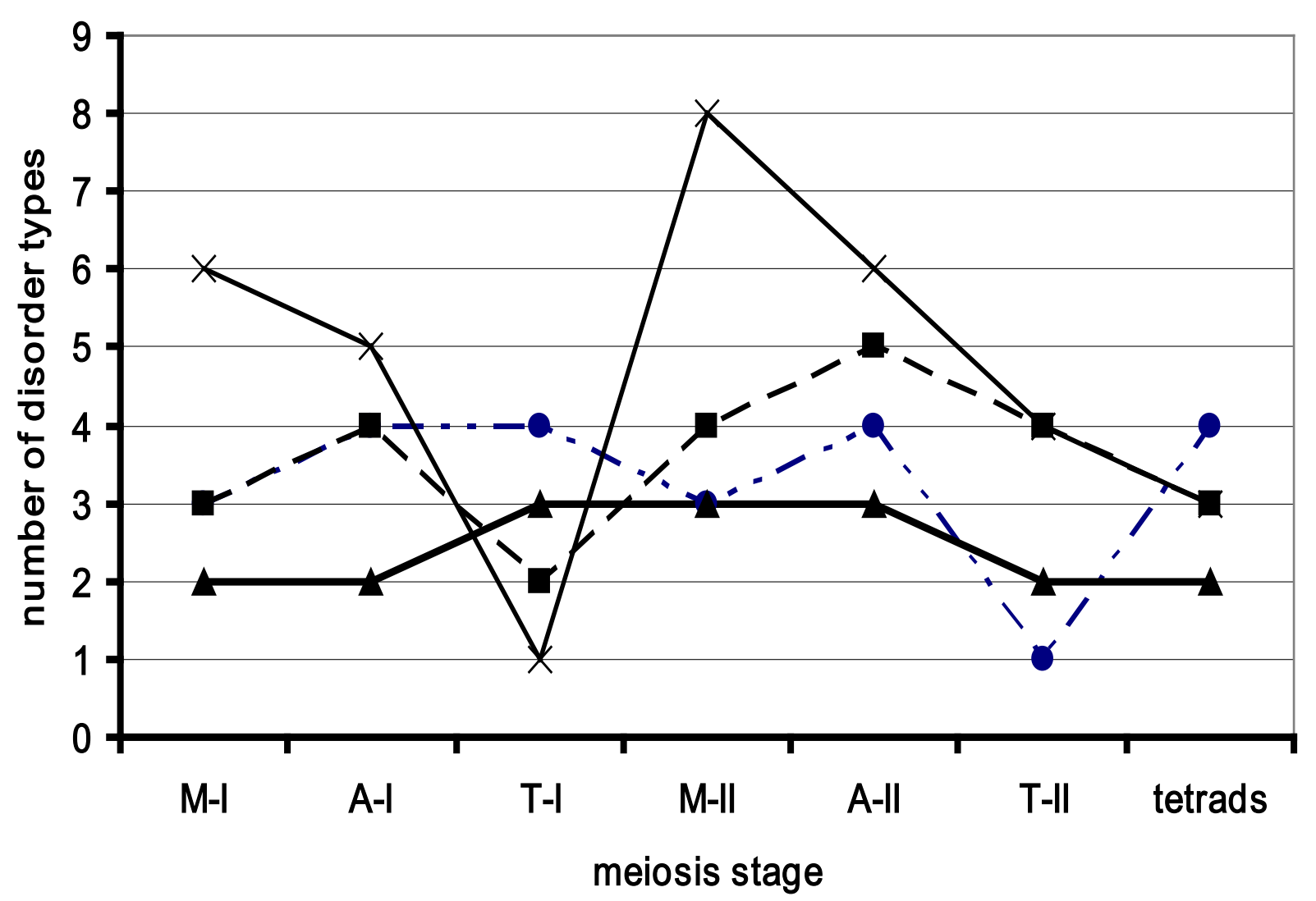

\section{- 25-35-121 - - f. 20-9-27 $\longrightarrow-25-37-47 \rightarrow 30-47-88$}

Figure 1. Number of disorder types in tetraploid apple forms

\section{Results}

If to analyze the meiosis process in tetraploid apple forms in comparison with diploid ones it may be noted that in most cases the diploid cultivars are characterized by correct microsporogenesis. For example, as Krylova, 1981 [14] reports, in conditions of Moldova the total number of disorders of microsporogenesis in diploid forms is $0,9-$ $4,7 \%$. According to our data, in conditions of the middle zone of Russia the number of disorders of microsporogenesis in tetraploid forms is $11,7-61,1 \%$, i.e. several times more.

Abnormal divisions occurred on all consecutive stages in all studied forms (Table 1).

According to the data in Table 2, the least number of disorder types was peculiar to 25-37-47 form; the greatest diversity of disorder types was observed in form 30-47-88. There was a certain relationship between the disorder amount and diversity of disorder types: form 25-37-47 was notable for the most correct meiosis in the process of microsporogenesis and a spectrum of disorders in it was minimal. On the contrary, in form 30-47-88 the per cent of disorders in the process of microsporogenesis was the highest one and the diversity of morphological types of disorders was maximal (Figure 1).

The disorders typical for a certain stage were observed in a majority of tetraploid forms (Figure 2). The occurrence of getting ahead of one or several chromosomes to the poles of division spindle (Figure $2 \mathrm{a}, \mathrm{b}$ ) and throwing of separate chromosomes outside of achromatinic spindle (Figure $2 \mathrm{c}$ ) were typical for the metaphase stage both in the first and second meiotic division. Besides, in anaphase-II and metaphase-II the over-numerous spindles occurred (Figure 2 d). That disorder was to a great extent peculiar for form 30-47-88, but sometimes it occurred in other forms. In anaphase-I and anaphase-II the main disorder was the backwardness of one or several chromosomes in the center of the spindle division (Figure 2 e,f). In telophase-I and telophase-II the presence of micronuclei was a predominant type of disorders (Figure $2 \mathrm{~g}$ ). Over-numerous nuclei (Figure $2 \mathrm{~h}$ ) and nuclei unequal in size were also typical for telophase-II. In the tetrad phase as a consequence of the previous disorder, was observed the presence of polyads (Figure 2 i) instead of normal tetrads and the presence of microspores with micronuclei. The major amount of polyads was noted in form 30-47-88. Polyads on a stage of tetrads made $46,4 \%$ from the total number of analyzed microsporocytes on that stage. Some less amount of polyads $-36,1 \%$, was noted in form 25-35-121. In forms 25-37-45 and 20-9-27 only 10,9 and 7,2 \% polyads were noted, respectively. 


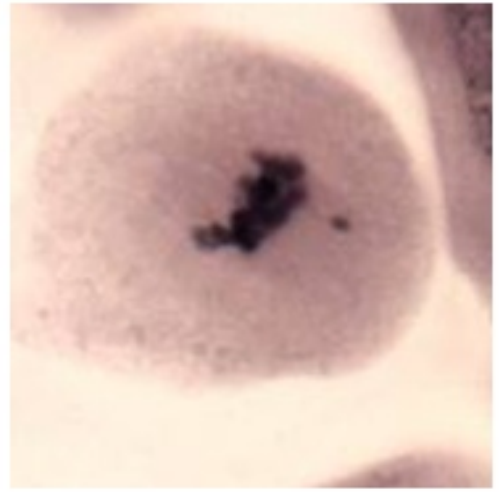

a.

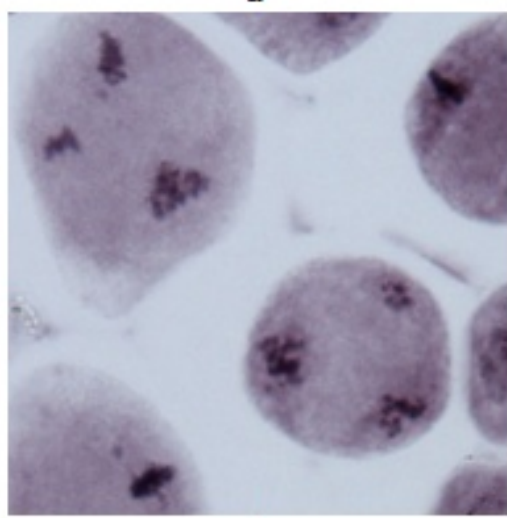

d

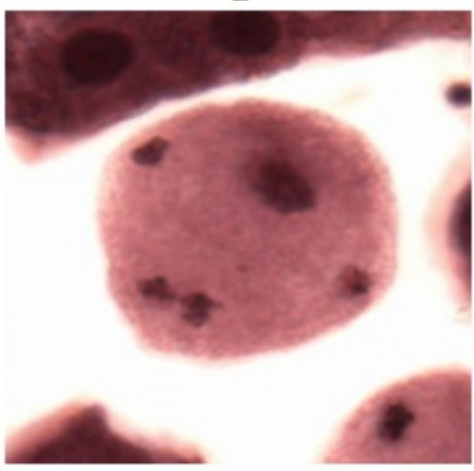

g

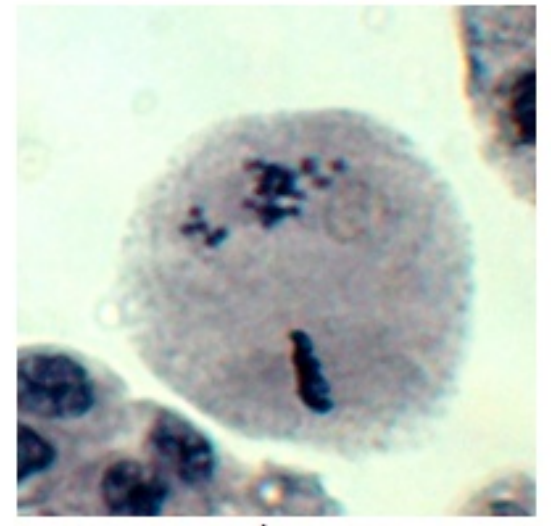

b

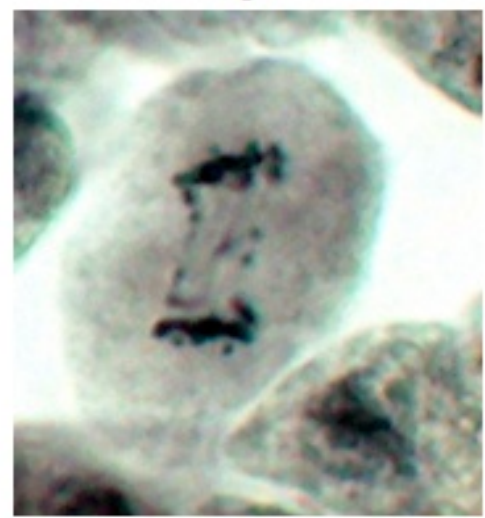

e

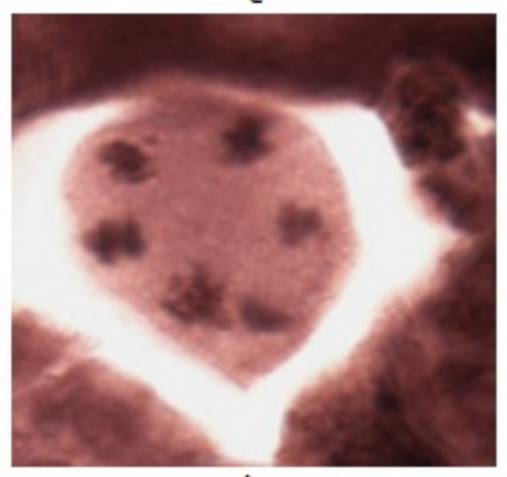

h

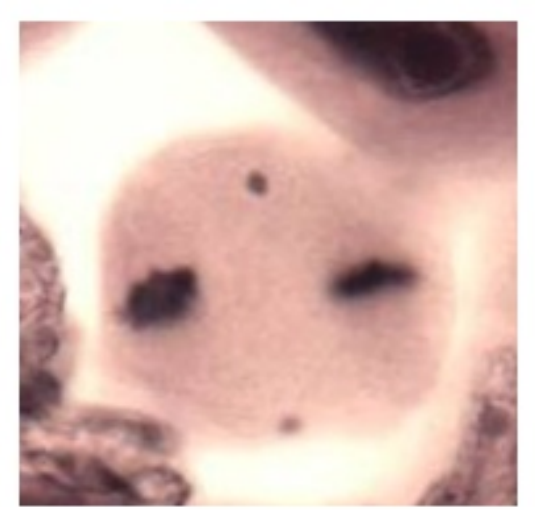

c

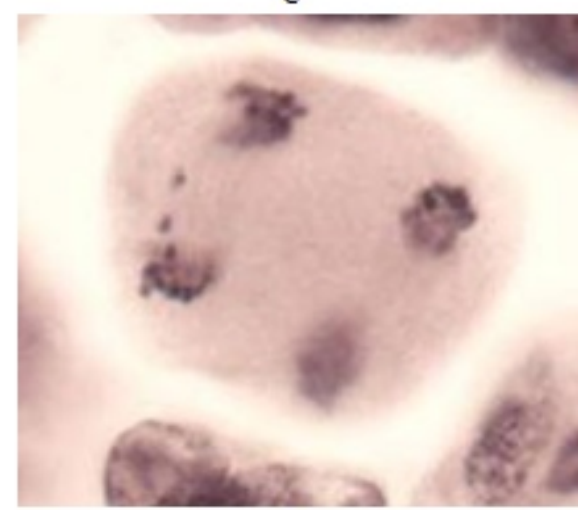

f

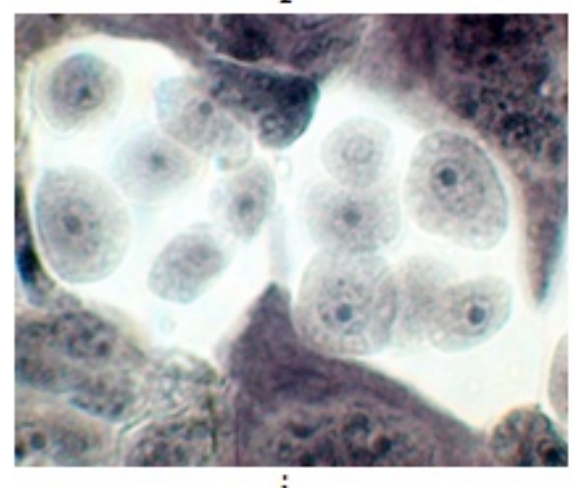

$\mathrm{i}$

A - metaphase-I, - getting ahead (25-37-47); b - metaphase-II, - getting ahead (3047-88); c - metaphase-II, - throwing outside (25-37-47); d - metaphase-II, over-numerous spindles (20-9-27); e - anaphase-I, - backwardness (30-47-88); f - anaphase-II, - (25-37-47), backwardness; g - telophase-II, - micronuclei (20-9-27); $\mathrm{h}$ - telophase-II, - over-numerous nuclei (20-9-27); i - stage of tetrads, - polyads (30-47-88).

Figure 2. Character of disorders in the process of microsporogenesis in new tetraploid apple forms 
In spite of some differences in the amount of disorders, the meiosis in the process of microsporogenesis in all studied forms had a general tendency (Figure 3)

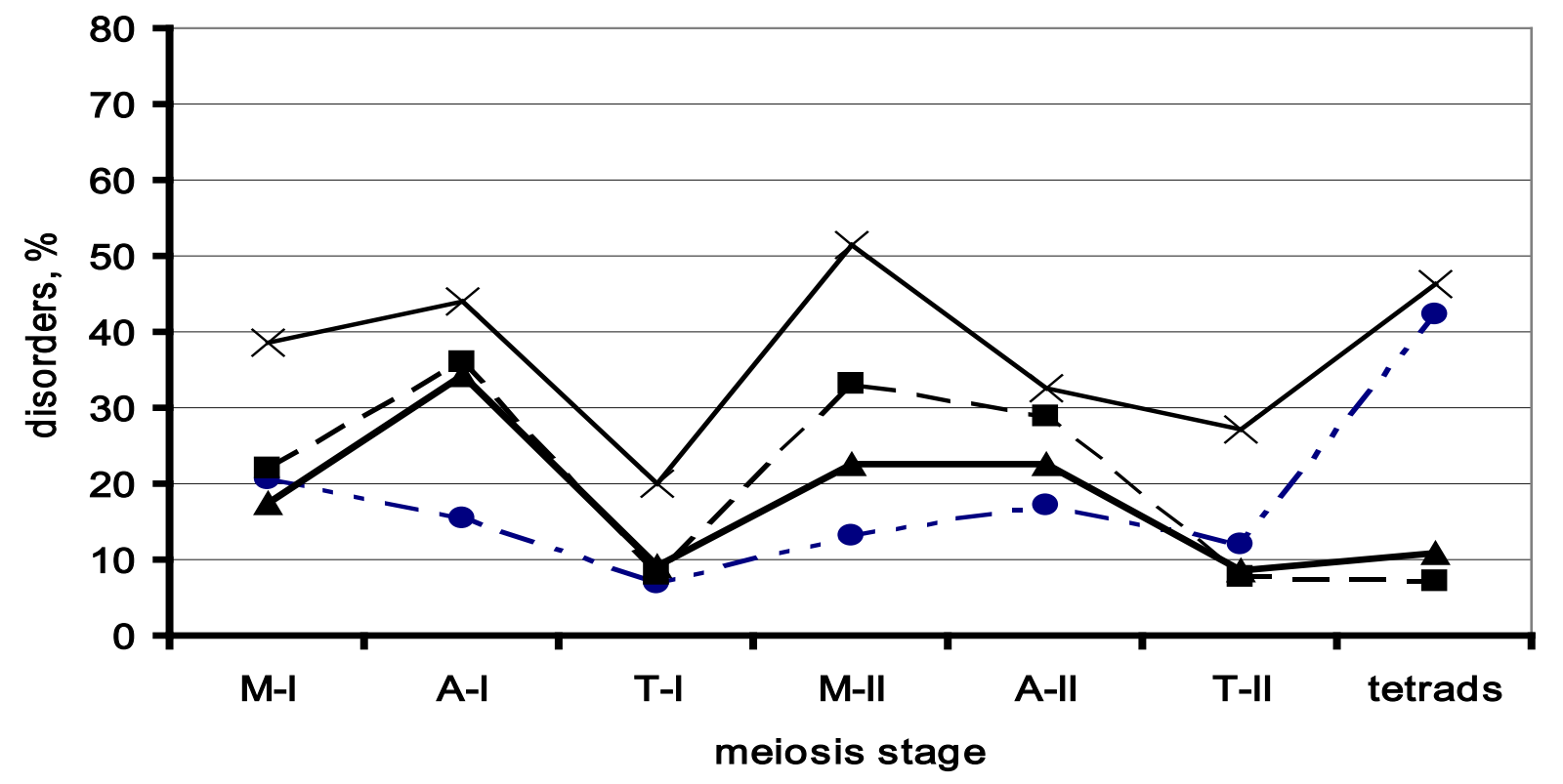

-0 - 25-35-121 - f. 20-9-27 $\longrightarrow 25-37-47 \multimap 30-47-88$

Figure 3. Meiosis process in tetraploid apple forms

Table 3. Ploidy of hybrid progeny in crossings $2 \mathrm{x} x 4 \mathrm{x}$ with new tetraploid forms as a tetraploid component

\begin{tabular}{|c|c|c|c|c|}
\hline \multirow{2}{*}{ Crossings } & \multirow{2}{*}{$\begin{array}{l}\text { Studied } \\
\text { Seedlings, } \\
\text { in all }\end{array}$} & \multicolumn{3}{|c|}{ Including } \\
\hline & & $\begin{array}{c}2 \mathrm{x} \\
\text { pieces } / \%\end{array}$ & $\begin{array}{c}3 \mathrm{x} \\
\text { pieces } / \%\end{array}$ & $\begin{array}{c}4 \mathrm{x} \\
\text { pieces } / \%\end{array}$ \\
\hline Diploid x 25-35-121 (4x) & 117 & $36 / 30,8$ & $80 / 68,4$ & $1 / 0,8$ \\
\hline Diploid x 25-37-47 (4x) & 65 & $10 / 15,4$ & $55 / 84,6$ & - \\
\hline Diploid x 30-47-88 (4x) & 205 & $62 / 30,2$ & $143 / 69,8$ & - \\
\hline
\end{tabular}

It should be noted that despite the significant number of disorders on different stages of microsporogenesis, all studied tetraploids formed the considerable quantity of normal pollen. The definition of pollen fertility and viability allowed concluding the possibility of using those forms as pollinators. Thus, when defining the pollen fertility by aceto-carmine method (Pausheva, 1980 [6]), the following results were obtained: Form $25-37-47$ had fertility $53,3 \%$; $20-9-27-94,5 \%$; 30-47-88 - 99,5\% and 25-35-121 - 44,2\%.

The analysis of ploidy of hybrid progeny obtained with the participation of those forms are evident of the fact that they are donors of diploid gametes and confirm their value as pollinators in crossings with diploid cultivars (Table 3).

\section{Conclusion}

Therefore, the application of these forms in the hybridization gives breeders a rich material for the further study and selection of new promising triploid cultivars. Forms $25-37-47$ and 30-47-88 are especially valuable, since they carry genes of the immunity to scab: 25-37-47 - gene $V_{m}$, 30-47-88 - gene $V_{f}$. It will allow obtaining new cultivars, which have along with favorable qualities so characteristic of triploids, as well immunity to such a harmful disease as scab. Consequently, the application of new tetraploid initial forms in the hybridization will favour the nearest fulfillment of apple assortment replenishment with new adaptive high-quality cultivars suitable for up-to-date intensive horticulture.

\section{REFERENCES}

[1] Tuz, A.S. Polyploid apple and pear cultivars / A.S. Tuz, A.Ya. Lozitsky // Genetics, 1970. - T. 6. - № 9. - p. 41-50.

[2] Bacharach, A. Western Fruit Grower. - 1982. - V. 102. - № 6. - p. 32.

[3] Singh, Wafai, BA. Euphytica, 1984. - V. 33. - № 1. - p. 
209-214.

[4] Barletta, M. Erwerbsobstbau. - 1988. - 30. 4. - p. 113-115.

[5] Topilskaya, L. A. Study of somatic and meiotic chromosomes of black currant on acetohematoxylin pressed preparations. / L. A. Topilskaya, S. V. Luchnikova, N. P. Chuvashina // Bulleten TzGL im. I. V. Michurina. - 1975. - V. 22. - p. 58-61.

[6] Pausheva Z. P. Practical work on plant cytology / Z. P. Pausheva // M. Kolos. - 1980. - 304 p.

[7] Shoemaker, J.S. Botan. Gaz. - 1926. - V. 81. - № 2. - p. 148-172.

[8] Rybin, V.A. Transactions on applied botany, genetics and breeding - 1927. - V. 17. - № 3. - p. 101-120.

[9] Heilborn, O. Svensk. Bot. Tidskr. - 1928. - 22. - p. 185-199.

[10] Darlington, C.D., Moffett, A.A. - J. Genet., - 1930. - V. 22. № 2. - p. 129-151.

[11] Ivanovskaya, E.V. Scientific reports of high school. Biological science. - 1962. - № 1.

[12] Konstantinov, A.V. Meiosis. - Minsk, Publishing house of Belorussian state university. - 1971. - p. 179.
[13] Radionenko, A.Ya. Genetics. - 1972, - V. 8 - № 4. - p. 21-32.

[14] Krylova, V.V. Apple embryology. - Kishinev: Shtiintza. 1981. $-148 \mathrm{p}$.

[15] Singh, R., Wafai, B.A., Koul, A.K. - Cytologia, - 1985. - № 50. - p. 811-823.

[16] Nebel, B. Gartenbauwiss., - 1929. - № 1. - p. 549-592.

[17] Vaarama, A. J. Hereditas. - 1948. - V. 34. - № 1.-2. - p. 147-160.

[18] Sedysheva ,G.A. Col. Selection, variety investigation, agrotechnics of fruit and berry crops/ Tula, Priokskoye publishing house. $-1985 .-$ p. 36-45.

[19] Sedysheva, G.A. Col. Selection and variety propagation of orchard crops. - Orel: VNIISPK, 1998. - p. 47-52.

[20] Sedysheva, G.A., Knyazeva, E.A. Col. New varieties and technology of fruit and berry crop cultivation for orchards of intensive type. - Orel, VNIISPK. - 2000. - p. 205-206.

[21] Sedysheva, G.A., Gorbacheva, N.G. Col. Selection and variety propagation of orchard crops. - Orel: VNIISPK. 2007. - p. $183-188$ 